\title{
Understanding Authentic Leadership Style: The Satya Nadella Microsoft Approach
}

\author{
Deepti Prakash, Meenakshi Bisla*, Shweta Gupta Rastogi \\ University School of Management Studies, Guru Gobind Singh Indraprastha University, New Delhi, India \\ Email: *Meenakshi.05016690019@ipu.ac.in
}

How to cite this paper: Prakash, D., Bisla, M., \& Rastogi, S. G. (2021). Understanding Authentic Leadership Style: The Satya Nadella Microsoft Approach. Open Journal of Leadership, 10, 95-109.

https://doi.org/10.4236/oj1.2021.102007

Received: February 26, 2021

Accepted: June 5, 2021

Published: June 8, 2021

Copyright (c) 2021 by author(s) and Scientific Research Publishing Inc. This work is licensed under the Creative Commons Attribution International License (CC BY 4.0).

http://creativecommons.org/licenses/by/4.0/

\begin{abstract}
The paper endeavours to analyze authentic dimensions of Leadership with Satya Nadella's leadership and his aggressive strategy leading to an increase in Microsoft's profitability. A total of 7 interviews of Nadella from 2014 to 2020 were coded in NVivo to prepare Word query, TreeMap and cluster analysis. Also, besides tweets associated with \#Satya Nadella were captured using NCapture and exported to NVivo to obtain the sentiments by performing sentiment analysis. The Twitter analysis of Nadella's personality is majorly positive and neutral which reflects his success and influence across the globe. The traits of Nadella are linked with authentic leadership style. The study discusses the latent dimensions for becoming a successful authentic leader that is highly recommended for leaders to boost their leadership skills and increase organization's profitability in this competitive world.
\end{abstract}

\section{Keywords}

Satya Nadella, Profitability, Authentic Leadership, Strategy, Vision, \#SatyaNadella

\section{Introduction}

The scenario of corporate crises due to rising frauds and scams worldwide has created stress among stakeholders. Stress can immensely damage the trust, the culture can even refrain an employee from discovering its potential creativity. These circumstances enable stakeholders to prefer leaders with higher integrity. In this context, leadership plays an important role in encouraging creativity and innovation among followers (Oke, Munshi, \& Walumbwa, 2009). In this context, authentic leadership has gained widespread attention in organizations. Thus, by developing the culture of authentic leadership an enhanced creative workforce can be expected in the organization (Chaudhary \& Panda, 2018). 
Leaders who present their true selves and lead others are known as authentic leaders. Authentic Leadership proposed by Walumbwa, Avolio, Gardner, Wernsing and Peterson (2008) is leadership behavior pattern that includes self-awareness, internalized moral perspective, relational transparency and balanced processing (Gardner \& Carlson, 2015; Miao, Humphrey, \& Qian, 2018). Millennials now make up the largest generation in the workforce. They are better educated, more tech-savvy, and have higher expectations than any other group prior. Millennial Employee Engagement Study conducted by Cone Communications found that three-fourth millennials are willing to accept a pay cut if they are working for a socially responsible company. Besides, Generation $\mathrm{Z}$ members, the newbie on the work front, values diversity when selecting a place to work. In a Forbes article, Karl Moore (Professor at McGill University) points out: The better you are at being an authentic leader, the more your millennial employees will appreciate you. He adds that millennials can detect a drop of inauthenticity in an Olympic-sized pool like our Caribbean reef shark friends. The actual driving force for Microsoft's growth and enormous profits in recent time is by endeavoring a handful of courageous authentic decisions under the Leadership of Satya Nadella. Microsoft's ranking is experiencing upside down for the last six years (Table 1). The magnifying glass on revenue and assets will help to identify the actual position more precisely (Table 1). Microsoft is experiencing stable growth after the change of leadership i.e., after 2014, when Nadella became the Chief Executive Officer (CEO).

Nadella took over from Steve Ballmer in 2014 and adopted a new vision and leadership style for Microsoft's unique journey. This paper examines the relationship between the leadership style of Nadella and his vision which supports the importance of precise balance between supportive leadership and innovative organizational culture for achieving the goal of high organizational performance. This study discusses the managerial implication for highly competitive Information and Technology (IT) organizations worldwide. The study examines the role of a leader in transforming a stagnant organization such as Microsoft under Balmer before 2014 (Table 2) into a high technological innovator accelerating up the scoreboard in Fortune 500 ranking. Nadella has acquired the dominant position in both "Fortune's Businessperson of the Year 2019" and "Best CEOs for Diversity 2020".

Table 1. Microsoft's Ranking in Fortune 500 (2019) under Nadella's leadership.

\begin{tabular}{ccccc}
\hline Ranking & Year & Revenue (\$ millions) & Profit (\$ millions) & Assets (\$ millions) \\
\hline 21 & 2020 & 125,843 & 39,240 & 286,556 \\
$\mathbf{2 6}$ & 2019 & 110,360 & 16,571 & 258,848 \\
$\mathbf{3 0}$ & 2018 & 89,950 & 21,204 & 241,086 \\
$\mathbf{2 8}$ & 2017 & 85,320 & 16,798 & 193,694 \\
$\mathbf{2 5}$ & 2016 & 93,580 & 12,193 & 176,223 \\
$\mathbf{3 1}$ & 2015 & 93,580 & 12,193 & 128,000
\end{tabular}

(Source: https://fortune.com/company/microsoft/fortune500/) 
Table 2. Microsoft's ranking in fortune 500 under Balmer's leadership.

\begin{tabular}{cccccc}
\hline Year & 2014 & 2013 & 2012 & 2011 & 2010 \\
\hline Ranking & $\mathbf{3 4}$ & $\mathbf{3 5}$ & $\mathbf{3 7}$ & $\mathbf{2 8}$ & $\mathbf{2 5}$ \\
Revenue & 77,849 & 73,723 & 69,943 & --- & --- \\
\hline
\end{tabular}

(https://fortune.com/fortune500/2012/microsoft-corporation/)

Nadella took the challenging job as CEO of Microsoft in 2014 when Microsoft was not at its best position. In 2014, Nadella joined as Chief Executive Officer who helped Microsoft to extricate and faced three major challenges mentioned below:

- Crashed stock prices of Microsoft;

- Competitors (Apple and Google) making super-profits;

- Introducing new mobile technology.

Microsoft is the fourth, world's highest valuable organization and has increased its value by $\$ 250$ billion (Fox, 2019) under Nadella's leadership, which makes it is the essence of this study. The paper endeavors to analyze authentic dimensions of Leadership with

Nadella's visionary leadership and his aggressive strategy was leading to an increase in Microsoft's profitability. It also discusses the latent dimensions for becoming a successful authentic leader that are highly recommended for leaders to boost their leadership skills and increase organization's profitability in this competitive world.

\section{Literature Review}

According to Walumbwa, Avolio, Gardner, Wernsing and Peterson (2008), authentic leadership ( $\mathrm{AL}$ ) is defined as "a pattern of leader behavior that draws upon and promotes both positive psychological capacities and a positive ethical climate, to foster greater self-awareness, an internalized moral perspective, balanced processing of information, and relational transparency on the part of leaders working with followers, fostering positive self-development". Self-awareness refers to the degree of awareness of one's strengths and weaknesses and their impact on other people. Internalized moral perspective signifies the importance of how one's values and moral standards regulate their behaviors and actions. Relational transparency relates to the degree to which how one shares information and display emotions openly. Balanced processing depicts the extent to which a leader uses the available information before arriving at a decision (Chaudhary \& Panda, 2018). These dimensions increase the level of balanced information treatment, transparency and relational work between a leader and his followers, in the way that positive self-development of followers is promoted (Semedo, Coelho, \& Ribeiro, 2017). The dimensions of being self-aware and relationally transparent and balanced processing of information help authentic leaders to encourage trust and positive interpersonal relationships among their followers (Avolio, Gardner, Walumbwa, Luthans, \& May, 2004; Walumbwa, Luthans, Avey, \& Oke, 2011). 
Authentic Leadership maximize the performance of followers and leads to positive work-related outcomes (Ribeiro, Gomes, \& Kurian, 2018b; Azanza, Gorgievski, Moriano, \& Molero 2018; Imam, Naqvi, Naqvi, \& Chambel, 2020). Authentic leader transparency in his decisions develops follower's commitment and builds strong attachments to the organization (Rukh, Shahrukh, \& Iqbal, 2018; Hlongwane \& Olivier, 2017). Empirical studies suggested that Authentic leadership is positively related to numerous necessary outcomes, for example, job satisfaction, Performance and creativity (Gardner, Cogliser, Davis, \& Dickens, 2011; Ribeiro, Duarte, \& Filipe, 2018a; Ribeiro, Duarte, Filipe, \& Torres de Oliveira, 2020).

Authentic leaders help promote a work environment wherein creativity is fostered and encouraged by involving specific actions guided by beliefs, values, and words, thereby contributing to a truthful and open relationship with their followers (Ilies, Morgeson, \& Nahrgang, 2005; Rego, Vitória, Magalhães, Ribeiro, \& Cunha, 2013). It has been suggested that authentic leaders positively influence employees' creativity (Avolio et al., 2004; Gardner, Avolio, Luthans, May, \& Walumbwa, 2005; Rego, Sousa, Marques, \& e Cunha, 2012, 2014; Rashid, Islam, Asif \& Ahmer, 2019). When close relationships between authentic leaders and employees are established then employees feel free to try new ideas. Research also shows that increasing employees' perceiving psychological safety and inherent motivation provides a fearless climate of working with new ideas (Cerne, Jaklic, \& Škerlavaj, 2013; Rego et al., 2012, 2014).

Further, Cottrill, Lopez and Hoffman (2014) suggested that developing selfawareness, transparency, ethics, and processing multiple perspectives as authentic leadership skills, will benefit the organizations by enhancing employee inclusion, commitment, self-esteem and organizational functioning.

\section{Research Methodology}

\subsection{Research Objectives}

The objectives of the study are

Objective 1: To depict Nadella's leadership journey at Microsoft through four dimensions of authentic leadership.

Objective 2: To examine the public sentiments of tweets regarding \#SatyaNadella in NVivo.

\subsection{Data Collection}

The researcher searched in the Google Scholar, Microsoft Academia, Harvard Business Review (HBR), newspapers, and websites. The search words like "authentic leadership", "Microsoft", "creative leadership", "innovation" and "Satya Nadella" were used to explore the literature. Initially 60 articles emerged which were further refined by following a trial search for each database by going through the abstract and full paper after that. A total of 29 research articles are obtained after removing duplicate and irrelevant articles. For Word Query analysis 
using Nvivo, only seven interviews of Nadella are obtained from https://www.businessinsider.in/ (2014), https://www.youtube.com (2015), https://www.theverge.com (2018), https://www.hbr.org (2017), https://www.wsj.com (2019), https://www.youtube.com (2019) and https://www.cncb.com (2020) to obtain word query analysis, treemap, cluster analysis. The interviews are available online either as audio or video which were transcribed into written form as a word document by researchers one by one. The researcher restricted searches for interviews for leadership of Nadella at Microsoft from 2014 until April 2020 for NVivo software analysis. The interviews are available online free of cost.

For sentiment analysis, \#SatyaNadella tweets data is obtained using NCapture from Tweeter to analyze the public opinion towards Nadella on $3^{\text {rd }}$ July 2020 in NVivo qualitative software. The tweets and retweets captured were 1531, but after removing irrelevant tweets from either unauthorized tweeter accounts or irrelevant tweets, the total count of tweets obtained was 1084. NVivo analytics aligned the characteristics and strategies of Nadella to the theory of authentic leadership to examine the relationship between the two using the 29 selected papers.

\subsection{Data Analysis Procedure and Techniques}

The interviews are available online either as audio or video which were transcribed into written form as a word document by researchers one by one. These seven interviews of Nadella from 2014-2020 were imported in QSR NVivo software. The nodes were classified as the four components of Authentic leadership theory mentioned above and references from each interview were taken into account to analyze the relationship between them. The word query tool was performed to analyzed using NVivo Qualitative analysis tool using the filter of a minimum of three words and stemmed approach (generalized) to obtain word cloud (Figure 1), treemap (Figure 2) and Cluster analysis (Figure 3).

To explore the personality of Nadella, tweets of \#SatyaNadella were extracted using NCapture on July 3, 2020 to find the general popularity of his personality. These tweets were analyzed using "Autocode" approach in NVivo tool using the option "to identify sentiment" based on each and every sentence mentioned in the tweets and retweets. The sentiment analysis represented the positive, negative, neutral and mixed sentiments towards Nadella (Figure 4), the tweets captured across the globe (Figure 5) and the representation of tweets collected network as Sociogram.

\section{Analysis and Discussion}

\subsection{Qualitative Analysis}

\subsubsection{Word Query of Nadella's Interview Performed in NVivo Software}

The seven interviews of Nadella from 2014-2020 were analyzed in NVivo using word frequency query tool with the filter of a minimum of three words and stemmed approach (generalized) to obtain word query analysis (Figure 1), tree 
map (Figure 2) and Cluster analysis (Figure 3). Figure 1 shows Nadella's concern about technology bound Microsoft. The relevant words were found to be "Satya", "Nadella", "Microsoft", "technology", "leadership", "innovation", “employees" and "culture". The greater the size of the word appears, the larger is the frequency of the word in word query analysis. It is interpreted from Figure 1 that Nadella focuses on the thinking part of how to inculcate change in his organization by innovating. To do so, he needed to change the leadership style and culture of Microsoft (Smale, 2019). This word query analysis displays Nadella's personality and establishes the relevancy of the interviews selected depicting Nadella.

Figure 2 shows the TreeMap obtained from NVivo Analytical tool performed on interviews of Nadella depicting the three broad themes as "microsoft", "think" and "thing". It represents that Nadella mostly speaks about Microsoft and thinks about it. The other relevant words depicting his focus are "technology", “create”, "product”, "people”, "learning”, "business", "satya”, "nadella”, "ceo" and "microsoft". The focus of Nadella is primarily on the need to create technology or products by developing a learning approach among people (employees in general) for a business. He motivates his employees to innovate and create new technology by continuous learning is depicted from treemap. His rank was 40 in the list of most powerful people 2018 by Forbes.

Figure 3 depicts the cluster analysis performed in NVivo Analytical tool using interviews of Nadella. The cluster analysis groups the words of one theme in one colour and other words of different themes into different colors. Here, the dark coloured theme is focusing on industry which is built on technology and culture. The change brought by Nadella in culture by focusing on building technology (Cloud-enabled AI) accelerated the revenues and transformed Microsoft (Table $1)$.

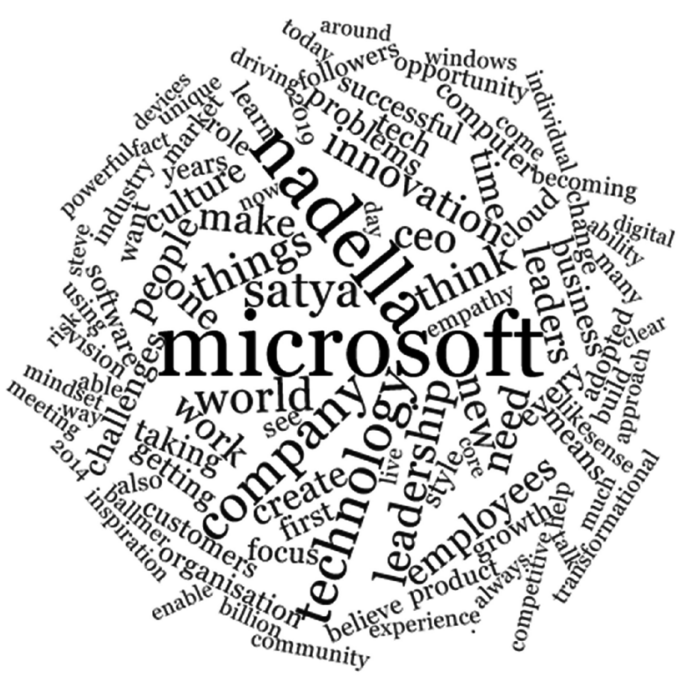

Figure 1. Word query analysis. (Exported from QRS NVivo Qualitative Software on January 2, 2021). 


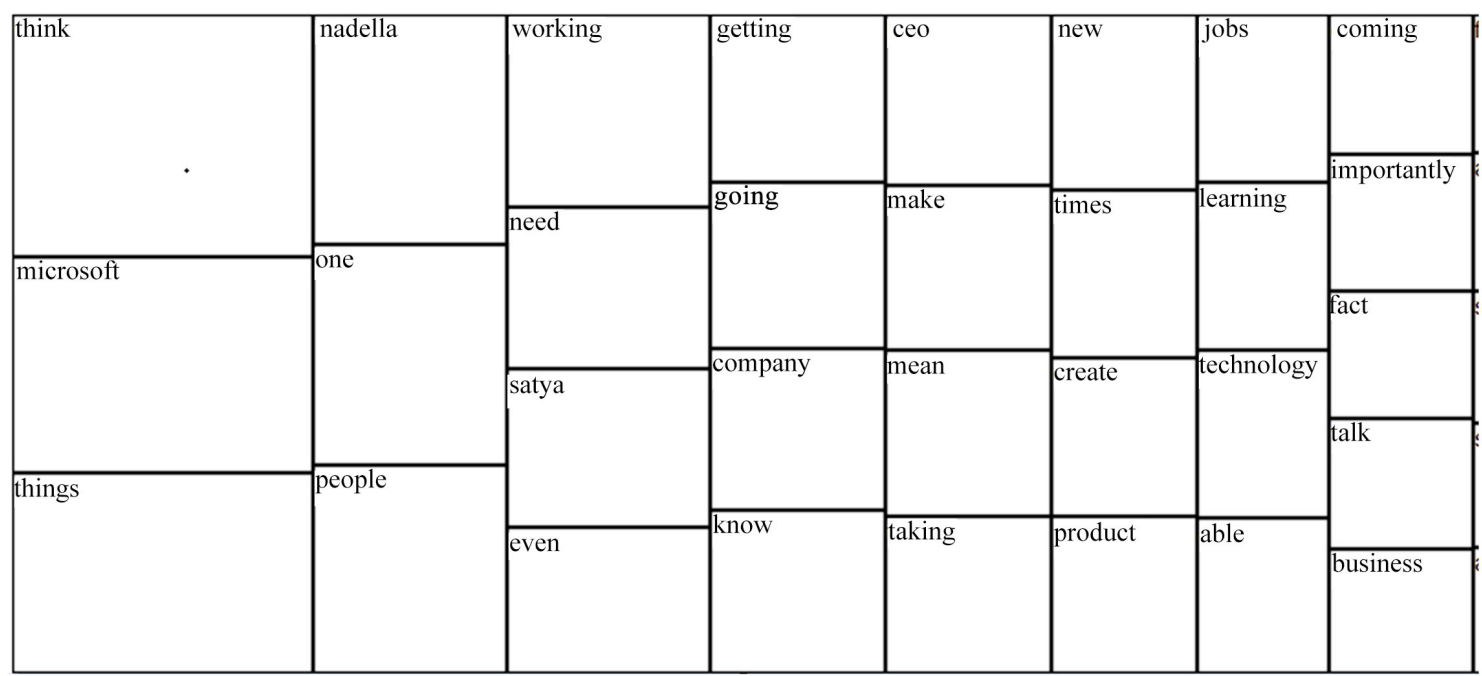

Figure 2. Tree map. (Exported from QRS NVivo Qualitative Software on January 2, 2021).

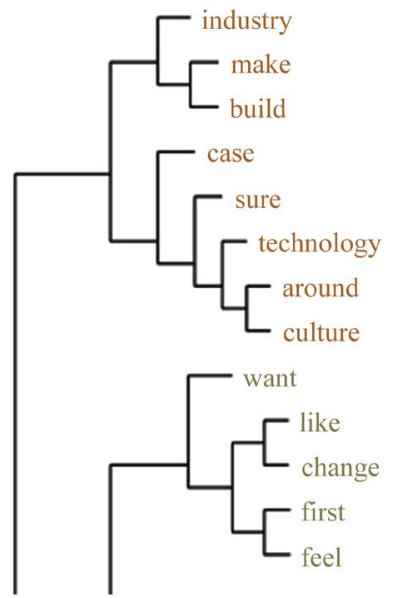

Figure 3. Cluster analysis. (Exported from QRS NVivo Qualitative Software on January 2, 2021).

\subsubsection{The Sentiment Analysis of Tweets \#SatyaNadella}

In pandemic, Microsoft is the first organization to provide 3 months parental leave to their employees whose schools were shut down due to pandemic situation in the world in early 2020. Microsoft provided a free of cost interface for promoting team work by developing "Microsoft Teams", which highlight its vision of embracing team work culture. Nadella is one of the leaders to help his employees in every possible circumstance observed from his initiatives. Moreover, over the past six years, Nadella has shown his leadership skills to embrace diverse culture and enhance Microsoft's profitability after joining as CEO in 2014. Because of his constant efforts to encirclement diversity, he has topped the list of "Best CEOs for Diversity 2020" voted by employees of color and indigenous individuals, reported by Comparably.

During this pandemic where all the organizations face critic's lens, the image of Nadella emerged to be positive by performing sentiment analysis using tweeter 
data (tweets obtained on June 32020 for \#SatyaNadella). The majority of the tweets are neutral and positive out of total 1084 tweets and retweets (Appendix). Figure 6 shows that the neutral and positive tweets account for $78 \%$ of the tweets, and the mixed and negatives tweets account for a mere $11 \%$ and $12 \%$ respectively.

The tweets obtained were from across the globe but more than $90 \%$ were obtained from North America as shown in Map in Figure 4.

The Sociogram Twitter in Figure 5 depicts the network of tweets and retweets obtained using the NVivo analytical tool. The sociogram appears to be like a ball which specifies that the retweets on the tweets of \#SatyaNadella were immensely spread like a web across the globe. Hence, the importance of examining Nadella's leadership traits in one of the most successful IT giants "Microsoft" is of immense importance. The leaders can learn a lot from Nadella's journey and personality as he is the first in the "Best CEOs for Diversity 2020" (Comparably, 2020).

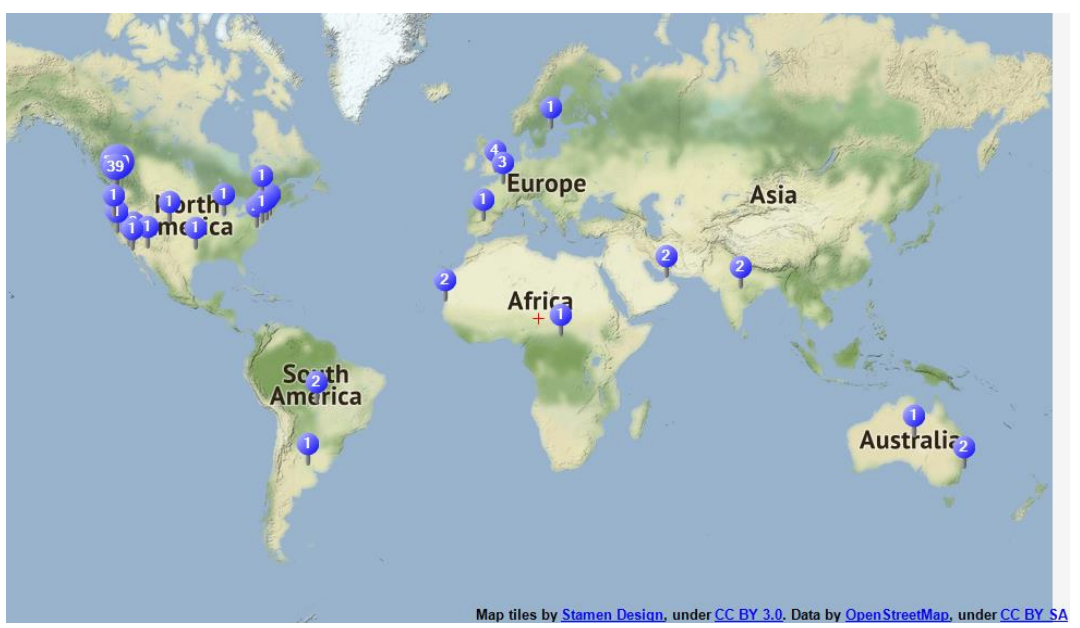

Figure 4. World Map of tweets \#SatyaNadella. (Exported from QRS NVivo Qualitative Software on January 2, 2021).

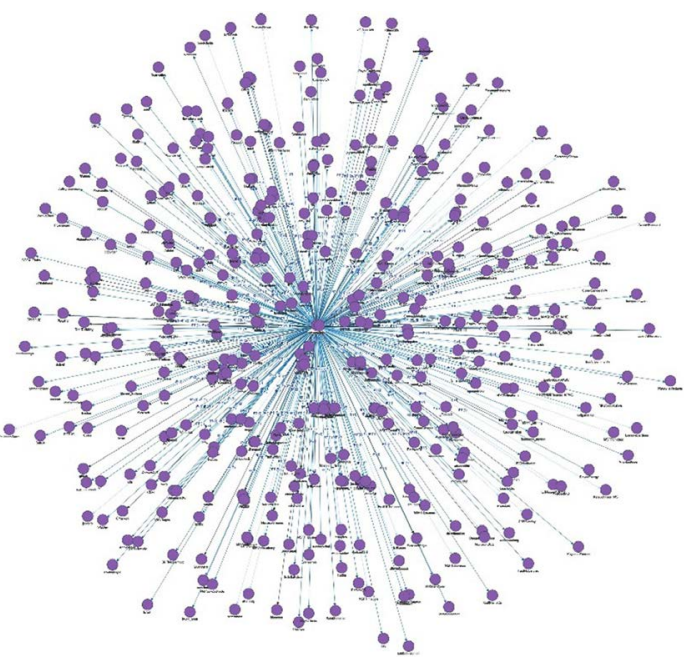

Figure 5. Sociogram Twitter of tweets \#SatyaNadella. (Exported from QRS NVivo Qualitative Software on January 2 2021). 


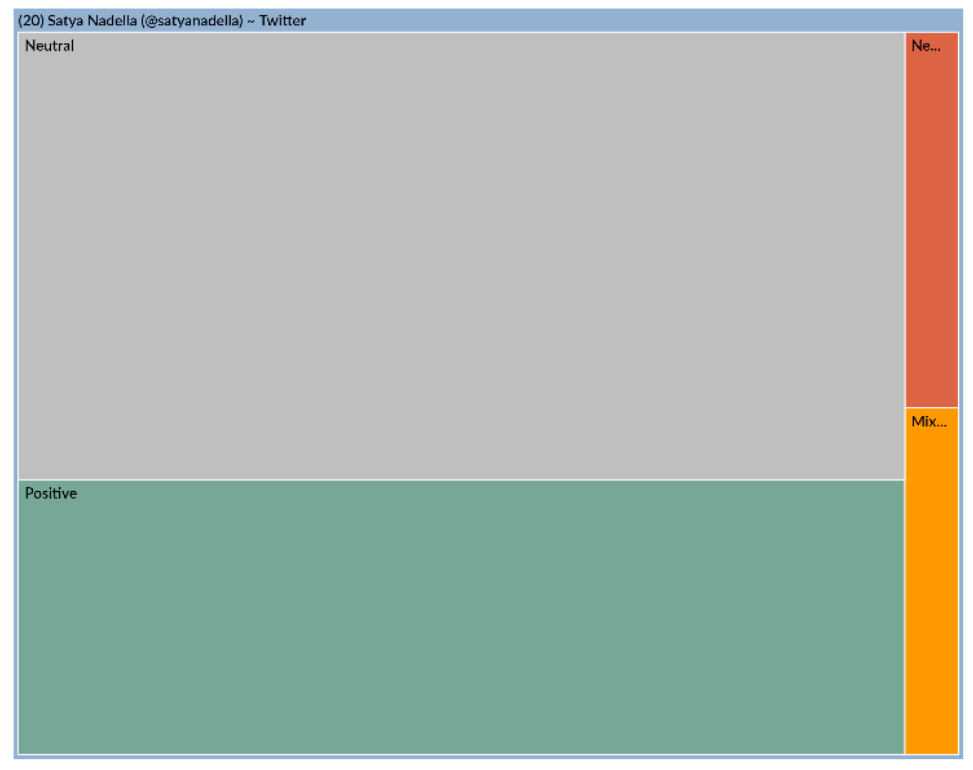

Figure 6. Sentiment analysis of Tweets \#SatyaNadella. (Exported from QRS NVivo Qualitative Software on January 2, 2021).

\subsection{Nadella's Journey and Leadership}

Nadella began his journey in Microsoft in 1992 as an engineer. He has evolved into a more productive and farsighted individual at Microsoft which is one reason behind his successful leadership style, he mentioned during his interview with $\mathrm{BBC}$. He explores the organization by examining its existing culture, then introducing new values, norms, shared assumptions and vision for smooth adopting a new culture he wants to incorporate. The roles performed by Nadella are, 1) to recognize the need to revitalization, 2) creating new vision, 3) institutionalizing change. Studies provide evidence for the importance of the positive effect of authentic leadership style on creativity (Rego et al., 2012, Rego et al., 2014). Walumbwa et al. (2008) classified authentic leadership into four components, "1) Self-awareness, 2) Relational transparency, 3) Internalized moral perspective and 4) Balanced processing." Comparing these characteristics with those of Nadella's, it is evident that the leadership style adopted by him involved many hurdles and vilipend comments from critics. Nadella joined and announced himself as an ordinary individual who focuses more on collaboration, learning, stimulate intellectuality and creativity. His approach for expected culture was results-driven instead of aggressiveness and competitive culture during Ballmer's days. Hence, Microsoft was on acceleration after Nadella joined as CEO. He had fulfilled the four characteristics of authentic leadership explained in Table 3.

After joining Microsoft in 2014, Nadella changed the leadership and culture by emphasizing embracing individual empowerment, positivity, empathy and growth of employees, according to article on Nadella's Leadership style in Berrett Koehler Publishers (2019). Let's bridge the gap between Nadella's initiative as CEOs and authentic leadership traits (Table 3). Firstly, he is an empathetic 
Table 3. Relationship between nadella's leadership style and authentic leadership.

\begin{tabular}{|c|c|c|c|}
\hline Sr No & Leader's skills & Definition & Nadella's ideologies depicting leader's skills (Example) \\
\hline 1 & Self-Awareness & $\begin{array}{l}\text { Authentic leaders exhibit the } \\
\text { awareness their strength, } \\
\text { weakness; express how others see } \\
\text { them and how he impacts others. } \\
\text { Leaders having a high level of } \\
\text { self-awareness can influence their } \\
\text { followers' choice of behaviour, } \\
\text { thinking, and motivate them to } \\
\text { encourage trust for building } \\
\text { positive interpersonal } \\
\text { relationships among their } \\
\text { followers, which eventually } \\
\text { promotes creativity. }\end{array}$ & $\begin{array}{l}\text { Nadella gained the top spot in "Best CEO for diversity } 2020 \text { " in Comparably Awards, } \\
\text { where employees of color voted i.e., employees think Nadella to be an inclusive leader } \\
\text { and who give equal opportunity to all irrespective of any color. He endeavoured } \\
\text { diversity and said diversity leads to new creative innovative ideas. Nadella's strength } \\
\text { lies in influencing followers to develop new ideas by providing brainstorming } \\
\text { sessions, giving equal opportunity to all, and his constant encouragement to work in } \\
\text { teams. He encourages employees to be innovative and creative by providing his } \\
\text { support, thus developing an environment of trust among employees. Also, followers } \\
\text { tend to feel good when he is around, depicting his positive interpersonal relationships. } \\
\text { He believes in Teamwork and thus introduced new features in Microsoft Teams i.e., } \\
\text { "Together Mode" for encouraging teamwork for everyone. Through Nadella's } \\
\text { declaration of doing meaningful work, he positively influences his employees to } \\
\text { develop innovative ideas to endeavour sustainability. His global skill initiative to help } \\
\text { others (not only his employees) is driven by his empathetic characteristics, which are } \\
\text { highly appreciated by individuals globally, improving Nadella and Microsoft's overall } \\
\text { impression. He communicated 3R to his followers that can help them to overcome } \\
\text { challenges faced } \\
\text { - Reacting, • Responding • Reimagining }\end{array}$ \\
\hline
\end{tabular}

Nadella openly communicated his expectation to his employees in three simple approach

Authentic Leaders display authentic selves because they openly share information, feelings, emotions, and thoughts with their followers. It provides an opportunity for their

\section{Relational} transparency

\section{followers to express their} opinions, ideas, and challenges. Authentic Leaders create an environment of honesty, openness, and trust for promoting creativity among their followers and encourage them to generate new ideas.
- Create clarity

- Strike energy

- Ability to achieve success

He hosts open sessions like "ask me anything" to encourage the forthcoming employees with ideas and develop a relationship of accessible information and trust He supports his followers, develops trust through his leadership style, and encourages teamwork among his employees. He gave way to brainstorming sessions and a new open work environment to enhance creativity. He collaborated with competitors to embrace innovation and creativity. He encourages employees to examine market critically and come up with innovative ideas

He is rated highest in interpersonal skills by his employees as they refer to him as a happening person and tagged him as most favorite individual. He allowed individual employees to create innovative ideas and support employees in creative yet risky projects. He encourages challenge taking behavior of employees.

Authentic leaders strongly express their consistent moral values and standards while comparing it to social, organizational, and team pressures. They also reveal how much their behaviours and decisions are aligned with internalized values. They promote integrity and honesty, and discourage unethical behaviours that lead to positive climate and trust and, thereby, creativity.
Nadella is rated as "Best CEO for Diversity 2020" depicting his high moral and ethical values regarding diversity and inclusivity. His values and fair decisions have imprinted him as best inclusive leader by the employees of color. He prefers diversity for enhancing creativity as he stated that Diversity inclusion is "A pillar for success." He addressed the social injustice in America by clearly communicating his commitment, through mail to all his employees, to take actions to control racial injustice, inequity, and unambiguously believe that "Black lives matter." He updated Microsoft policies and taking initiatives to make Black lives better by providing technological support to individuals of color. Nadella's behaviour is consistent with his moral value of embracing inclusive diversity to enhance creativity

He believes in happier customers, employees and partners by focusing on "inclusivity, trust \& sustainability." 
Authentic leaders analyze the entire information objectively before making a decision, improving fairness in decision-making to promote positive interpersonal relationships and trust, which eventually develops an emotional attachment among followers towards their organizations and enhances creativity.
Collaborating with rival firms and taking risks to encourage team work and grow with them. The collaboration brings trust in leader's role for enhancing creativity. Nadella's his initiative to bring education back on track by working with a partner is highly appreciated by his followers. His three meeting rules i.e., $\bullet$ listen more $\bullet$ talk less $\bullet$ be decisive, became very popular. He intends to combine the fragments of Microsoft into one.

After examining the environment, Nadella stated that the world is heading towards transforming from the traditional work culture into new a hybrid work system and culture. He calls it the new regular work, which focuses on results rather than the number of hours logged in. This decision has encouraged employees to be more productive and developed a sense of attachment for Nadella in pandemics.

and inclusive leader who gives importance to diversity to generate new innovative ideas and motivate employees to develop new ideas by organizing brainstorming sessions. His influence on others and his high level of self-awareness undoubtedly makes him the "Best CEOs for Diversity 2020" (reported by Comparably) depicting his strength. Secondly, he was considered the most happening person and rated highest in his interpersonal skills by his fellow mates in Microsoft over the last five years showing his strong interpersonal skills. Also, he provided an opportunity to be heard with the help of strong communication channel conducting "ask me anything sessions" depicting his relational transparency characteristics. Thirdly, his verge of building a culture of trust around the concept of equitable growth with "inclusivity, trust and sustainability" shows his strong internalized moral perspective. Lastly, the balanced approach of Nadella is depicted by his supportive style and clear vision of being a partner led company, collaborating with rival firms to generate innovative ideas and positively communicating a sense of new hybrid system of work for transforming world. He empowered his employees to examine the market critically and develop innovative ideas and hence increase creativity. Therefore, Nadella is an authentic leader who has changed the Microsoft's phase from status quo to accelerated rate and fulfils the four component of Authentic Leadership theory (Walumbwa et al., 2008).

The word query tool (word query, treemap and cluster analysis) depicts Nadella's personality as Microsoft's CEO and sentiment analysis of \#SatyaNadella reports a majorly positive opinion of the tweets. The traits of Nadella are found to be linked with four components of authentic leadership. The challenges and approaches adopted by Nadella in Microsoft lays down benchmarks for other potential leaders present and to come in the future.

\section{Implications}

As a leader, Nadella promoted employee innovation and creativity that enhanced Microsoft's performance. It has been suggested that creativity increases when fair decision making and analysing the character of leader increases (Oke et al., 2009). Nadella's approach of "Never Say NO" and supportive style for empow- 
erment has increased Microsoft's ranking in terms of Revenue and Total Assets (Table 1). This style incidents that an integrated culture should be provided that can help followers to explain their own ideas and decisions that may develop creativity. This study suggests that authentic leadership style is very conducive to the creation of a good team atmosphere of psychological safety and trust which in turn facilitates employee willingness and creativity. It is also suggested that a leader promote an atmosphere of respect, admiration, participation, support, and involvement for his/her employees from diverse backgrounds to enhance the commitment and creativity. Nadella embraces diversity culture by putting the hands up for the campaign "Black Lives Matter" that has acknowledged him as the "Best CEOs for Diversity 2020" reported by Comparably (2020). So, the above-mentioned dimensions provide a base to Nadella's visionary leadership, making it possible for Microsoft to become the world's fourth most valuable company globally (Fox, 2019). The unique vision and farsightedness of Nadella, being an authentic leader and the journey of transformation of Microsoft has provided crucial lessons that can be learned by fellow IT giants such as Facebook, Google and Apple.

The findings of the analysis indicate some practical contributiosn from integrated Nadella-authentic leadership style that has developed a culture of innovation and creativity. First, leaders should give followers the choice of thinking and behaviour. Second, they should motivate and encourage trust for building positive interpersonal relationship that can promote creativity. Third, freedom and opportunity should be provided to followers to express their opinion and ideas. Fourth, a leader should promote integrity, honesty and discourage unethical behaviours that lead to positive climate and trust and therefore creativity. Fifth, develop an emotional attachment among followers towards their organisation. Sixth, he should focus on collaboration, learning, empowerment, positivity, empathy and growth of employees. Lastly, develop opportunity of voice to be heard and a good communication channel should be integrated to develop a culture of trust that can promote creativity. Hence, these suggestions can help leaders to polish and develop their leadership skills and organisation performance. These suggestions are applicable not only to IT giants but also to any other business in $21^{\text {st }}$ century.

\section{Conclusion}

This study makes significant contributions by displaying how Nadella skills contribute to employee innovation through creativity. This study highlights relationship between Nadella's skills and Authentic Leadership dimensions of selfawareness, relational transparency, balanced processing and an internalized moral perspective. These dimensions are quite important as they encourage employees' positive attitudes and behaviours (i.e., affective commitment and creativity). In this study we have tried to analyze these dimensions with Nadella's visionary leadership of authenticity. Identification of sentiments associated with 
\#SatyaNadella is obtained using NCapture from Twiter. The tweets mainly were neutral and positive. The study also signifies that the traits of Nadella are linked with authentic leadership style with the help of his interviews and decisions taken by Nadella since 2014 (Table 3). The study further discusses the implications for the fellow competitor's IT giants such as Apple, Facebook and Google to learn lessons from the "Transformation of Microsoft" for smooth cultural change and accelerating profits over the years (Sharma, 2020).

\section{Conflicts of Interest}

The authors declare no conflicts of interest regarding the publication of this paper.

\section{References}

Avolio, B. J., Gardner, W. L., Walumbwa, F., Luthans, F., \& May, D. R. (2004). Unlocking the Mask: A Look at the Process by Which Authentic Leaders Impact Follower Attitudes and Behaviors. The Leadership Quarterly, 15, 801-823.

https://doi.org/10.1016/j.leaqua.2004.09.003

Azanza, G., Gorgievski, M. J., Moriano, J. A., \& Molero, F. (2018). Influencing Salespeople's Work Outcomes through Authentic Leadership. Leadership \& Organization Development Journal, 39, 926-944. https://doi.org/10.1108/LODJ-05-2017-0113

Cerne, M., Jaklic, M., Škerlavaj, M. (2013). Authentic Leadership, Creativity, and Innovation: A Multilevel Perspective. Leadership, 9, 63-85.

https://doi.org/10.1177/1742715012455130

Chaudhary, R., \& Panda, C. (2018). Authentic Leadership and Creativity. International Journal of Productivity and Performance Management, 67, 2071-2088.

https://doi.org/10.1108/IJPPM-02-2018-0082

Comparably (2020). Best CEOs for Diversity 2020.

https://www.comparably.com/news/best-companies-for-diversity-2020

Cottrill, K., Lopez, P. D., \& Hoffman, C. C. (2014). How Authentic Leadership and Inclusion Benefit Organizations. Equality, Diversity and Inclusion: An International Journal, 33, 275-292. https://doi.org/10.1108/EDI-05-2012-0041

Forbes, Fortune 500 (2019). https://fortune.com/fortune500/2019

Fox, M. (2019). Examining the Leadership Style of Microsoft CEO, Satya Nadella. https://ideas.bkconnection.com/examining-the-leadership-style-of-microsoft-ceo-satya -nadella

Gardner, W. L., \& Carlson, J. D. (2015). Authentic Leadership. International Encyclopedia of the Social \& Behavioral Sciences, 27, 245-250.

https://doi.org/10.1016/B978-0-08-097086-8.22001-1

Gardner, W. L., Avolio, B. J., Luthans, F., May, D. R., \& Walumbwa, F. (2005). Can You See the Real Me? A Self-Based Model of Authentic Leader and Follower Development. Leadership Quarterly, 16, 343-372. https://doi.org/10.1016/j.leaqua.2005.03.003

Gardner, W. L., Cogliser, C. C., Davis, K. M., \& Dickens, M. P. (2011). Authentic Leadership: A Review of the Literature and Research Agenda. The Leadership Quarterly, 22, 1120-1145. https://doi.org/10.1016/j.leaqua.2011.09.007

Hlongwane, V., \& Olivier, B. (2017). Authentic Leadership Influences on Organizational Commitment in a South African State Hospital. Journal of Psychology in Africa, 27, 
400-404. https://doi.org/10.1080/14330237.2017.1375204

Ilies, R., Morgeson, F. P., \& Nahrgang, J. D. (2005). Authentic Leadership and Eudaemonic Well-Being: Understanding Leader-Follower Outcomes. The Leadership Quarterly, 16, 373-394. https://doi.org/10.1016/j.leaqua.2005.03.002

Imam, H., Naqvi, M. B., Naqvi, S. A., \& Chambel, M. J. (2020). Authentic Leadership: Unleashing Employee Creativity through Empowerment and Commitment to the Supervisor. Leadership \& Organization Development Journal, 41, 847-864. https://doi.org/10.1108/LODJ-05-2019-0203

Miao, C., Humphrey, R. H., \& Qian, S. (2018). Emotional Intelligence and Authentic Leadership: A Meta-Analysis. Leadership \& Organization Development Journal, 39, 679-690. https://doi.org/10.1108/LODJ-02-2018-0066

Oke, A., Munshi, N., \& Walumbwa, F. O. (2009). The Influence of Leadership on Innovation Processes and Activities. Organizational Dynamics, 38, 64-72. https://doi.org/10.1016/j.orgdyn.2008.10.005

Rashid, M. A., Islam, T., Asif, R., \& Ahmer, Z. (2019). Impact of Authentic Leadership on Employees Creativity and Innovation: Mediating Role of Psychological Capital. Journal of the Research Society of Pakistan, 56, 61.

Rego, A., Sousa, F., Marques, C., \& e Cunha, M. P. (2012). Authentic Leadership Promoting Employees' Psychological Capital and Creativity. Journal of Business Research, 65, 429-437. https://doi.org/10.1016/j.jbusres.2011.10.003

Rego, A., Sousa, F., Marques, C., \& e Cunha, M. P. (2014). Hope and Positive Affect Mediating the Authentic Leadership and Creativity Relationship. Journal of Business Research, 67, 200-210. https://doi.org/10.1016/j.jbusres.2012.10.003

Rego, A., Vitória, A., Magalhães, A., Ribeiro, N., \& e Cunha, M. P. (2013). Are Authentic Leaders Associated with More Virtuous, Committed and Potent Teams? The Leadership Quarterly, 24, 61-79. https://doi.org/10.1016/j.leaqua.2012.08.002

Ribeiro, N., Duarte, A. P., \& Filipe, R. (2018a). How Authentic Leadership Promotes Individual Performance. International Journal of Productivity and Performance Management, 67, 1585-1607. https://doi.org/10.1108/IJPPM-11-2017-0318

Ribeiro, N., Duarte, A. P., Filipe, R., \& Torres de Oliveira, R. (2020). How Authentic Leadership Promotes Individual Creativity: The Mediating Role of Affective Commitment. Journal of Leadership \& Organizational Studies, 27, 189-202. https://doi.org/10.1177/1548051819842796

Ribeiro, N., Gomes, D., \& Kurian, S. (2018b). Authentic Leadership and Performance: The Mediating Role of Employees' Affective Commitment. Social Responsibility Journal, 14, 213-225. https://doi.org/10.1108/SRJ-06-2017-0111

Rukh, L., Shahrukh, H. M., \& Iqbal, K. Z. (2018). Effect of Authentic Leadership on Organization Commitment: Mediating Role of Job Satisfaction. Journal of Entrepreneurship \& Organization Management, 7, 247-248.

Semedo, A. S., Coelho, A., \& Ribeiro, N. (2017). Authentic Leadership and Creativity: The Mediating Role of Happiness. International Journal of Organizational Analysis, 25, 395412. https://doi.org/10.1108/IJOA-03-2016-0994

Sharma, P. (2020). The Transformation of Microsoft. Fortune India. https://www.fortuneindia.com/opinion/the-transformation-of-microsoft/104658

Smale, B. (2019). London Business School Review, Issue 1.

Walumbwa, F. O., Avolio, B. J., Gardner, W. L., Wernsing, T. S., \& Peterson, S. J. (2008). Authentic Leadership: Development and Validation of a Theory-Based Measure? Journal of Management, 34, 89. https://doi.org/10.1177/0149206307308913 
Walumbwa, F. O., Luthans, F., Avey, J. B., \& Oke, A. (2011). Authentically Leading Groups: The Mediating Role of Collective Psychological Capital and Trust. Journal of Organizational Behavior, 32, 4-24. https://doi.org/10.1002/job.653

\section{Websites}

https://blogs.microsoft.com/blog/2020/06/23/addressing-racial-injustice/

https://news.microsoft.com/2020/06/30/microsoft-to-help-25-million-people-worldwideacquire-new-digital-skills-needed-for-the-covid-19-economy/

https://www.businessinsider.in/tech/enterprise/news/presenting-satya-nadella-employeda-growth-mindset-to-overhaul-microsofts-cutthroat-culture-and-turn-it-into-a-trillion -dollar-company-heres-how-he-did-it/articleshow/74528714.cms

https://www.cloudwars.co/microsoft/microsoft-hypergrowth-beyond-azure-q4-2020-earn ings-call/

https://www.cnbc.com/2018/07/17/how-microsoft-has-evolved-under-satya-nadella.html https://www.comparably.com/news/best-companies-for-diversity-2020/

https://www.crn.com/news/channel-programs/satya-nadella-s-5-biggest-statements-at-m icrosoft-inspire-2020

https://www.edition.cnn.com/2020/04/09/tech/microsoft-12-weeks-parental-leave/index. $\underline{\mathrm{html}}$

https://www.forbes.com/powerful-people/list/\#tab:overall

https://www.forbes.com/powerful-people/list/\#tab:youngest

https://www.fortune.com/fortune500/2019/microsoft/

https://www.fortuneindia.com/opinion/the-transformation-of-microsoft/104658

https://www.inc.com/jessica-stillman/the-3-characteristics-all-great-leaders-share-accordi ng-to-microsoft-ceo-satya-nadella.html

https://www.london.edu/lbsr/changemakers-satya-nadella

https://www.microsoft.com

https://www.microsoft.com/en-us/microsoft-365/blog/2016/11/02/introducing-microsoft -teams-the-chat-based-workspace-in-office-365/

https://news.microsoft.com/2018/03/29/satya-nadella-email-to-employees-embracing-our -future-intelligent-cloud-and-intelligent-edge

https://news.microsoft.com/en-in/microsoft-forecasts-hybrid-new-normal-of-work-in-in dia/

https://news.microsoft.com/skills/

https://www.qz.com/work/1539071/how-microsoft-ceo-satya-nadella-rebuilt-the-compan y-culture/

https://www.reuters.com

https://www.technologyrecord.com/magazine/the-record/summer-2020 